\title{
openheart Severe aortic stenosis patient risk during the COVID-19 pandemic
}

Jasimuddin Ahamed

To cite: Ahamed J. Severe aortic stenosis patient risk during the COVID-19 pandemic. Open Heart 2020;7:e001355. doi:10.1136/ openhrt-2020-001355

Accepted 3 September 2020

Check for updates

(c) Author(s) (or their employer(s)) 2020. Re-use permitted under CC BY-NC. No commercial re-use. See rights and permissions. Published by BMJ.

Cardiovascular Biology Research Program, Oklahoma Medical Research Foundation, Oklahoma City, Oklahoma, USA

Correspondence to Dr Jasimuddin Ahamed; ahamedj@omrf.org
Aortic stenosis (AS) is a progressive aortic valve disease that can lead to heart failure, syncope and sudden death if not treated. Severe AS currently affects more than 2 million people over 65 years of age in the USA. The only treatment option for AS is valve replacement by either surgical aortic valve replacement (AVR) or the less invasive transcatheter aortic valve replacement (TAVR), also called transcatheter aortic valve implantation (TAVI). AVR requires intensive care unit (ICU) admission, whereas TAVR can be performed in a non-ICU setting. Both procedures are commonly associated with complications, such as stroke. ${ }^{1}$ Bleeding and thrombosis are also potential complications of these procedures. Given the considerable morbidity and mortality, patients with these postoperative complications are admitted to the ICU for management.

SARS-CoV-2, which causes COVID-19, has become a pandemic and has caused high mortality rates among the elderly. Currently, there is no vaccine against SARS-CoV-2, and there is no effective treatment to treat patients with severe COVID-19. More than 730000 people worldwide and over 160000 in the USA have died from COVID-19 as of 10 August 2020 according to Johns Hopkins Coronavirus Resource Center; these figures are expected to continue to rise until there are effective vaccines and therapies. Treating patients with COVID-19 during this pandemic requires many medical resources. Importantly, acute respiratory distress syndrome and multiorgan failures, believed to be due to systemic and pulmonary thrombosis, ${ }^{23}$ are common symptoms of severe COVID-19 that require treatment in the ICU. Therefore, government officials have recommended ceasing almost all elective surgeries until the COVID-19 pandemic is under control. ${ }^{4}$ Although many patients with symptomatic AS can delay procedures intended to alleviate their symptoms, some may require lifesaving procedures. In cases where life-saving procedures (AVR or TAVR) are required,
SARS-CoV-2 infection can be an additional and very dangerous comorbidity. Therefore, I suggest that the following points should be considered:

1. Low-risk, asymptomatic patients who can delay their procedures must stringently avoid infection, for instance by following guidelines for hygiene and wearing masks, and should continue to maintain strength and endurance as much as possible by routine exercise.

2. Patients with severe symptomatic AS should discuss the potential benefits and risks, including the new risk of comorbidities with COVID-19 that can be life threatening, of hospitalisation with their cardiologists. Therefore, physicians should have all pertinent information to identify the appropriate procedure, considering both AVR and TAVR approaches. The patient risk assessment typically includes patient age and surgical risk; however, given the increased general risk of the procedure and that SARS-CoV-2 infection can be an additional and very dangerous comorbidity, suggesting the less invasive TAVR should be considered.

3. COVID-19 may predispose some patients to thrombosis, and there are instances in which standard heparin-based anticoagulants, even at full dosage, are ineffective in preventing ongoing thrombosis. ${ }^{5}$ AS patients therefore may have increased risk for developing thromboembolic complications during the valve replacement procedure or during subsequent hospitalisation and recovery if they are infected with SARS-CoV-2. Although most patients with severe COVID-19 who develop thrombosis develop venous thrombosis, some also develop arterial thrombosis. In fact, a recent study showed that a prosthetic aortic graft thrombosis patient died from COVID-19 and that anticoagulant and thrombectomy procedure were unsuccessful. ${ }^{6}$ Therefore, the risk of prosthetic valve implantation should be seriously considered. If this pro- 
cedure is deemed necessary, then thrombus formation must be carefully monitored.

4. Although not approved for treating COVID-19, antiviral drugs (eg, ritonavir/lopinavir) and the potential antiviral drug hydroxychloroquine are in clinical trials and being used empirically to treat patients with COVID-19. The use of ritonavir/lopinavir and hydroxychloroquine are associated with cardiovascular disease. The antiviral drug remdesivir has shown some initial promise in treating COVID-19 and has received Emergency Use Authorization from the US Food and Drug Agency to treat patients hospitalised with severe COVID-19. There are no reports to date assessing the effect of remdesivir on thrombosis or cardiovascular disease, including AS. However, the effects of these drugs on valvular disease, thrombosis and other cardiovascular disease cannot be ruled out.

5. Clearly, patients with COVID-19 are highly prothrombotic with unknown aetiology. D-dimer is markedly elevated in many patients, and meta-analysis revealed its association with disease severity and mortality. ${ }^{7}$ Therefore, it is critical to determine which anticoagulant should be used in addition to the normal prophylaxis regimens, since these are not very effective in patients with COVID-19. Recent data from our group, showed a superior effect of the direct thrombin inhibitor, argatroban in reducing circuit thrombosis and D-dimer, whereas therapeutic dosage of heparin failed to prevent thrombosis. ${ }^{5}$ Therefore, direct thrombin inhibitors should be considered for AS patients who test positive for SARS-CoV-2, since both COVID-19 and AS procedure can increase the risk of thrombosis.

6. If AS patients have COVID-19 and shortness of breath, the risk of morbidities is increased, as shortness of breath can be caused by either COVID-19 or AS. Under such circumstance, echocardiography is important for accurate diagnosis of the status of the patient's AS. If the shortness of breath is not caused by AS, markers for COVID-19, such as interleukin-6, D-dimer and complement proteins and white cell counts, and acute white cell counts should be examined, as these levels should not rise in stable AS patients. If, however, the respiratory symptom is the result of AS, which can be fatal in itself, TAVR may be a better option than AVR considering the very high-risk status of patients with COVID-19 comorbidities. Concurrent monitoring of the status of AS by echocardiography will avoid the complicating comorbidity of thrombosis, for which there are currently no clear treatment guidelines for patients with COVID-19.

7. SARS-CoV-2 enters human cells by binding of the viral spike protein to the membrane-bound form of the aminopeptidase ACE2 on cells. ACE2 plays an important regulatory role in the renin-angiotensin system, which regulates normal and pathological vascular tone and blood pressure. Various types of medications that inhibit this system are used to treat patients suffering from cardiovascular disease, including those with AS, although none successful in clinical trial for AS. Studies in animals have suggested that inhibitors of this system can upregulate ACE2 expression, which led some investigators to postulate that patients receiving those inhibitors may be at high risk of contracting a SARS-CoV-2 infection, which needs to be validated experimentally. ${ }^{8}$ Therefore, it is critical to carefully assess and differentiate symptoms in acute AS versus COVID-19 cases wherein comorbidities and risk always rise. If the AS patient cannot delay life-saving procedures and are taking the ACE inhibitors, which can be discontinued but, as discussed above, other challenges, such as management of thrombosis, also need careful consideration.

The disease-causing mechanisms of both AS and COVID-19 are not well known. Both are associated with high-risk underlying conditions, including age, obesity, diabetes, hypertension and male gender, which increases the complexity of comorbidities and decision making, especially in the ICU setting when patients are on ventilators and oral treatments are not an option. Thus, understanding the mechanisms of these two diseases is required to improve treatments of these diseases separately as well as when they occur together. Because it is almost impossible to test the mechanism of AS or COVID-19 in humans, other than correlative studies, animal studies are needed. We have established a new robust mouse model of AS that simulates AS in human and identified platelet transforming growth factor beta-1 as a major driver of AS progression. ${ }^{9}$ The new SARS-CoV-2 animal models ${ }^{10}$ can be adapted to comorbid disease models, such as AS, to facilitate the identification of underlying mechanisms. These models will potentially inform the development of therapies for AS and COVID-19. Finally, COVID-19 may pose an additional risk for other life-saving procedures where thromboembolic events are common, such as cardiac catheterization, implantation of permanent pacemaker and left ventricular assist device in heart failure patients or thrombus removal in stroke patients. Thus, caution should be taken if these procedures are deemed necessary; in particular, thrombosis and the effects of anticoagulants on bleeding must be carefully monitored.

Acknowledgements The authors would like to thank Life Science Editors and M K Occhipinti for editing the manuscript and Dr J Laurence, MD, for his critical comments.

Contributors JA conceive the idea and wrote the manuscript.

Funding The work of the author herein is supported by NHLBI grant \# HL123605 and HL148123 (JA) and the laboratory of JA was supported by GM114731, CA213987, OCASCR and PHF grants.

Competing interests None declared.

Patient consent for publication Not required.

Provenance and peer review Not commissioned; externally peer reviewed.

Open access This is an open access article distributed in accordance with the Creative Commons Attribution Non Commercial (CC BY-NC 4.0) license, which permits others to distribute, remix, adapt, build upon this work non-commercially, and license their derivative works on different terms, provided the original work is properly cited, appropriate credit is given, any changes made indicated, and the use is non-commercial. See: http://creativecommons.org/licenses/by-nc/4.0/. 
ORCID iD

Jasimuddin Ahamed http://orcid.org/0000-0001-6455-0296

\section{REFERENCES}

1 Smith CR, Leon MB, Mack MJ, et al. Transcatheter versus surgical aortic-valve replacement in high-risk patients. $N$ Engl J Med 2011;364:2187-98.

2 Magro C, Mulvey JJ, Berlin D, et al. Complement associated microvascular injury and thrombosis in the pathogenesis of severe COVID-19 infection: a report of five cases. Trans/ Res 2020;220:1-13.

3 Connors JM, Levy JH. COVID-19 and its implications for thrombosis and anticoagulation. Blood 2020;135:2033-40.

4 How to handle elective surgeries and procedures during the COVID-19 pandemic. The National Law Review 2020.
5 Seshadri M, Ahamed J, Laurence J. Circuit thrombosis reversed and markers of a hypercoagulable state decreased by direct thrombin inhibition in COVID-19.

6 Giacomelli E, Dorigo W, Fargion A, et al. Acute thrombosis of an aortic prosthetic graft in a patient with severe COVID-19-Related pneumonia. Ann Vasc Surg 2020;66:8-10.

7 Shah S, Shah K, Patel SB, et al. Elevated D-dimer levels are associated with increased risk of mortality in COVID-19: a systematic review and meta-analysis. Cardiol Rev 2020. doi:10.1097/ CRD.0000000000000330. [Epub ahead of print: 02 Jul 2020].

8 Jarcho JA, Ingelfinger JR, Hamel MB, et al. Inhibitors of the reninangiotensin-aldosterone system and Covid-19. N Engl J Med 2020;382:2462-4.

9 Varshney R, Murphy B, Woolington S, et al. Inactivation of plateletderived TGF- $\beta 1$ attenuates aortic stenosis progression in a robust murine model. Blood Adv 2019;3:777-88.

10 Bao L, Deng W, Huang B, et al. The pathogenicity of SARS-CoV-2 in hACE2 transgenic mice. Nature 2020;583:830-3. 